\title{
Fostering Interdisciplinary Research in Universities: A Case study of Leadership, Alignment and Support
}

Tony Townsend, Professor and Chair

Public Service, Educational Leadership and management

School of Education

The University of Glasgow

Glasgow,UK

$+44(0) 1413304434$

tony.townsend@glasgow.ac.uk

John Pisapia, Professor

Department of Educational Leadership and Research Methodology

Florida Atlantic University

Florida, USA

jpisapia@fau.edu

Jamila Razzaq, Research Associate

School of Education

The University of Glasgow

Glasgow, UK

jamilarazzaq1@hotmail.com

Corresponding author:

Tony Townsend,

School of Education, University of Glasgow,

11 Eldon Street, Glasgow, G3 6NH, UK.

tony.townsend@glasgow.ac.uk

6738 words, plus 3 tables, abstract and references

The authors would like to express their gratitude to the Adam Smith Foundation, University of Glasgow, UK for the support of this research. 


\begin{abstract}
The aim of this paper is to describe actions designed to foster interdisciplinary research efforts at a major university in the United Kingdom. The study employed a descriptive mixed method case study approach to collecting and analyzing the data used to draw its conclusions. One hundred and twenty seven academic staff responded to the survey. The results of the survey were verified by 25 interviews with heads of colleges, heads of schools, research coordinators, research team leaders, and team members. These interviews were supported by document review to support the findings.

Leadership is important at the college and university levels if interdisciplinarity is to thrive. According to the data, this seems to have not yet occurred at this particular institution. The University has done well with most of the big structures that enrich and support interdisciplinarity. However, 'small' structures such as clarity of meaning, motivation of staff, misalignment of old structures, time and workload, and loss of identify have impeded the move to university wide interdisciplinarity.

A series of three recommendations are made to move the interdisciplinary project forward: stay clear on focus, extend the benefits of serendipity to more people, and remembering that one size does not fit all.
\end{abstract}

Key Words - restructuring, multidisciplinary research, interdisciplinary research, leadership, social networks. 


\section{'Crossing boundaries is a defining characteristic of our age.' \\ Julie Thompson Klein $(1996,1)$}

\section{Context of the study}

This paper considers a single case of a university in the United Kingdom that underwent a restructuring exercise to improve its research profile as part of its overall aim, as expressed in its 2010 strategic plan as being to 'enhance our position as one of the world's great, broad based, research intensive universities '(Great Western University $\left.{ }^{1}, 2010\right)$. This was the foreground to a background that saw an increasingly competitive research environment where both government and private funders wanted their funds to be spent supporting 'major social challenges' with 'research that has "impact". To compete for these funds, it was perceived that colleagues from a number of different discipline areas needed to partner with each other to come up with a concerted approach to the work at hand.

Although there were other reasons for restructuring the university, it seemed that the issues of research, and in particular interdisciplinary research, were always identified at the top of the list. In a number of different papers, presentations and public meetings, the following two factors always seemed to take priority:

- Facilitate collaboration to promote interdisciplinarity and joint working

- Facilitate improved research performance

The following research objectives listed within the restructuring proposal included:

- Remove internal barriers to collaboration and multi-disciplinarity in both research and teaching

- Bring together academically coherent groupings to optimise the University's ability to deliver its strategic objectives

- Provide the best opportunities to improve our research performance, developing our activities to better align with funding opportunities and thereby 'future-proofing' the University

\footnotetext{
${ }^{1}$ Pseudonym
} 
The strategy for enabling these objectives was simple. The University's current structure of seven faculties and more than fifty individual departments would be collapsed into four colleges containing 19 departments, with six research institutes established that would cut across colleges to enable a university wide focus on critical areas of research. The current study documents the perceptions of academic staff and university leaders about issues associated with interdisciplinary research after almost two years since the restructuring took place.

\section{Towards an understanding of Interdisciplinarity}

The purpose of this work is not to elevate interdisciplinary research over disciplinary research but to shed light on the attitudes, processes and practices which enable it, and how the disciplinary foundations supporting it can be strengthened. This purpose is important because interdisciplinary thinking is rapidly becoming an integral feature of research as a result of the inherent complexity of nature and society, the need to solve societal problems and the power of new technologies. The National Academy of Science argued (National Academy of Sciences, 2004, ix)

...that science and engineering research continually evolves beyond the boundaries of single disciplines and offers employment opportunities that require not only depth of knowledge but also breadth of knowledge, integration, synthesis, and an array of skills. Several reports suggested that a greater emphasis on interdisciplinary research and training would be consistent with those findings.

This approach has met with both acclaim and numerous debates in universities about the value and risks of interdisciplinarity, as well has how such efforts can be enhanced. While many scholars believe that the boundaries where disciplines intersect lead to new knowledge, and innovative approaches to problem solving (Fischer 2004; Huutoniemi et al. 2010), little empirical research has been conducted on the practices and processes which support it. The potential for interdisciplinary research to produce novel insights is generally accepted by funders of research, think tanks, and university administrators (National Academy of Sciences, 2004). It is less well accepted by disciplinary researchers. 


\section{Crossing borders}

Disciplines use borders to differentiate their work from others. These borders are formed by the assumptions, theories, techniques, tools and methods used to organize academic work and are embodied in the degrees the discipline offers. When academics decide to cross disciplinary borders they are working in an interdisciplinary fashion (Pirrie et al, 1998). The National Academy for Sciences $(2004,2)$ defines interdisciplinarity in this way:

Interdisciplinary research (IDR) is a mode of research by teams or individuals that integrates information, data, techniques, tools, perspectives, concepts, and/or theories from two or more disciplines or bodies of specialized knowledge to advance fundamental understanding or to solve problems whose solutions are beyond the scope of a single discipline or area of research practice.

There are many ways of working and conducting research in an interdisciplinary fashion e.g., multidisciplinary, transdisciplinary and cross disciplinary. Disciplinary research is conducted from the confines of one discipline. Multidisciplinary research infers that two or more disciplines work in conjunction on a common subject but from the boundaries of their discipline in an isolated manner (Salter \& Hearn 1996; Stokols, et al., 2008b, S79; Wall and Shankar 2008). They afford different perspectives on the issues at hand (Dykes et al. 2009), but academic boundaries are not crossed.

In interdisciplinary research there is an assumption of interdependence, in that the theories, perspectives, tools, and findings of one discipline cannot solve or illuminate the problem it is trying to solve so there is a sharing of purpose and methods, and development of understanding of the core principles of the contributing disciplines (National Academy of Sciences 2004; Boix, Mansilla \& Duraising 2007; Clark, 1993; Dykes et al. 2009; Klein 1990; Stokols, et al., 2008b; Wall and Shankar 2008). While there may be problems associated with working as an interdisciplinarian, there are also tremendous benefits. The allied discipline benefits since they get to see how their theories apply to other fields. The interdisciplinarian benefits because it helps them gain a more holistic view of the problem under investigation. Society benefits because the intersection of problems which are complex and seemingly intractable is where innovation is created. 
Transdisciplinary research means that members have developed sufficient trust and mutual confidence to transcend disciplinary boundaries and adopt a more holistic blended integrated approach so that the disciplinary distinctions become blurred which may result in the creation of new disciplines, such as biochemistry, bioengineering, and cognitive neuroscience (Dykes et al. 2009; Stokols, et al., 2008b). While theoretically there is a difference between interdisciplinary and transdisciplinary they are really in gradations (Dykes et al. 2009; Huutoniemi et al. 2010). For purposes of this paper, we follow Stokols et al., (2008a) and use the words synonymously as interdisciplinary research and we consider cross disciplinary in the same manner.

What can be seen from the above discussion is that there are levels of disciplinary interactions, collaboration, and integration that differentiate the terms - multidisciplinary, interdisciplinary, and even transdisciplinary and cross disciplinary. The more convoluted, complicated, and intractable the problem, the more researchers are inclined to collaborate and seek interdisciplinary lenses and methods to understand, interpret and solve the problems they investigate. However, these concepts are used ambiguously on many university campuses, among professionals, and funders of research.

\section{Promoting Interdisciplinarity}

Interdisciplinarity can be generated either from the bottom up or the top down (National Academy of Sciences, 2004). In the current study, although instances of bottom up generation have been documented, the current paper focuses on the top down initiation of a 'culture of interdisciplinarity'. A survey conducted by the National Academy of Sciences (2004, p. 86) identified the three most accepted ways to promote interdisciplinary research were to 'foster a collaborative environment, to provide faculty incentives including hiring and tenure policies that reflect and reward involvement in IDR, and to provide seed money for IDR projects.'

The same survey identified that the majority of respondents felt that there were institutional barriers to promoting such research. The most important of these included:

- time,

- resources devoted to facilitating interdisciplinary research having to be diverted from existing research and staffing resources, 
- the existing academic reward systems for hiring, promoting and rewarding staff, may only reward research from which the department receives credit, thus prioritising single discipline research,

- the individual disciplines likely to be called on to undertake IDR may have different sets of customs, values and understandings about what constitutes valuable research and how it should be undertaken,

- departments may have programme evaluation responsibilities that focus on specific areas that might conflict with IDR.

(National Academy of Sciences, 2004)

Further issues that are barriers to IDR include budgetary issues, such as who controls the resources, how cost-recovery is determined, allocations of teaching and research time and space, and the time it takes for IDR to be developed and then commence. Part of this is due to the need for faculty and students to learn the language and culture of the other discipline. (Metzger \& Zare, 1999)

There are strategies that institutions might use to promote IDR including supporting collaborations that address large social, environmental or other issues (Branscomb, Holton \& Sonnert, 2001) by allowing and supporting students and staff to explore the overlaps that disciplines have. (National Academy of Sciences, 2004) The current study will consider whether Great Western University has addressed the issues that promote and support the development of IDR and has overcome the obstacles, identified elsewhere, that prevent this from moving smoothly.

\section{Study Aims}

The current paper focuses on a two-phase, mixed methods descriptive case study designed to examine interdisciplinary dispositions, processes, and practices in conducting and nurturing interdisciplinary research teams. Two central questions guided the research:

1. What are the perceptions of administrators and academic staff of the nature and benefits of interdisciplinary research?

2. How is interdisciplinary research, at the University, College, and School level, organized, led, and supported? 
The results of this study will be of particular importance to universities since academics tend to live in worlds where individual accomplishment is more recognized than service to colleagues, institutions and students. This study will also provide evidence that informs a proposed new way of thinking about leadership in University settings.

\section{Theoretical Considerations}

Constructs are lenses that people use to understand phenomena and guide their efforts in bringing about personal and organizational change. Historically, leadership theory framed the tasks as the relationship between leaders, followers and common goals (Burns, 1978; Bass, 1990; Blake \& Mouton, 1961; Fiedler, 1967; Fu \& Yukl, 2000; Hershey \& Blanchard, 1988; House, 1971; Triandis, 1995). This theoretical position has served well in leading people in vertical relationships [e.g., leader - follower - common goals] where command, control and persuasion tactics are the levers of change. It serves less well in leading people and groups in horizontal relationships where collaboration, co-creation, coordination, minimum specifications, chunking change, and generative processes are the levers of change (Pisapia, 2009).

The move toward horizontal leadership requires skills to create direction, alignment and commitment, work in teams, and to develop community, which is suggested by distributed leadership theory (Cox, Pearce, \& Perry, 2003; Gronn, 2002; Pearce \& Conger, 2003); complexity science (Goldstein, Hazy, \& Lichtenstein, 2010; Lichtenshein et al., 2006; Uhl-Bien, Marion, \& McKelvey, 2007); and relational theories (Drath, 2001, McNamee \& Gergen, 1999; Uhl-Bien, 2006).

What this suggests for interdisciplinary research is that a key to success is to organize around the concept of a working alliance where there is agreement on direction, tasks and commitment (Drath, McCauley, Paulus, Velsor, O’Connor \& McGuire, 2008; Pisapia 2009) and where leaders focus on the process more than the content of the work to engage their colleagues rather than telling them what to do (Basadur, 2004).

\section{Method}

Using a constructivist mindset we used a two-phased mixed method descriptive case study to examine the interdisciplinary dispositions of academic staff, and the processes and practices used 
to conduct and nurture interdisciplinary research teams at one university. The study was conducted on the campus of Great Western University, a broad-based, research intensive institution, in the United Kingdom. It has more than 23,000 students from 120 countries and is in the top $1 \%$ of the world's universities.

\section{Research Design}

The case study method allowed for an intensive and rich description of forms of interdisciplinary and how it was nurtured in a real life context. This approach is most appropriate when the phenomenon of interest has a level of complexity that requires multiple data sources and methods to gain an in-depth understanding (Yin, 2003).

Our assumption in using this approach is that collecting diverse types of data provides a deeper understanding of our data. In executing this design we followed Cresswell's (2009) suggestions. A complete review of methods utilized is provided in Pisapia, Townsend \& Razzaq (2012).

The sampling strategy was purposeful in that participants' were chosen for their relevance to the research question (Miles \& Huberman, 1994). One hundred and twenty seven surveys were returned for analysis. Respondents were promised confidentiality.

Second, qualitative data were gathered through individual interviews from 25 administrative and academic staff within the university to clarify and illuminate the survey data gathered. Interviews included the vice principal of research and heads of three of the four colleges in the university, 5 school heads, 2 college level research coordinators, 2 school level research coordinators, 6 research team leaders and 6 research team members.

Interviews focused on three general questions related to interdisciplinary research teams (a) how were they formed, (b) what makes them work or not work, and (c) what can be done to nurture and support them. The interviewer provided an overview of the research project and then posed the three questions to enable a more informal conversational approach, to gather participants' insights and to help illuminate findings from the survey (Yin, 2003).

Archival data were also collected from university websites, publications, and official university documents, strategic plans and implementing documents and presentations to the governing board. 


\section{Data Analysis}

The data analysis for this study was guided by the conceptual framework and research questions and Yin's (2003:126) advice that data analysis 'consists of examining, categorizing, tabulating, testing, or otherwise recombining evidence, to draw empirically based conclusions.' Survey, narrative, and interview data were coded by respondent group. This coded data and the archival data were then grouped to the research question prompt by the research team to form three evidence sheets.

Themes that emerged from the survey, interviews and written narratives were triangulated with documents. The researchers looked for patterns and themes as well as contrasts and paradoxes (Coffey, Holbrook, \& Atkinson, 1996). When the evidence sheets were finalized, the research team used a process of constant comparison to identify findings under each of the research questions and then to identify the evidence that supported the finding. Using three sources, (a) academic staff (b), work unit managers, and (c) organizational archival data, reduced the likelihood of common method bias (Podsakoff, MacKenzie, Lee, \& Podsakoff, 2003) and strengthened the internal validity of findings.

\section{Results}

The results are organized as follows. First the sample is described. Then the findings are organized by research question. Verbatim quotes and other rich narrative data are provided to help readers determine the trustworthiness of findings and how the findings transfer to other settings. The narrative and interview data is reported by the roles the respondent fills at the university. Academic staff who did not identify themselves are coded AS. Others were coded as $\mathrm{CH}=$ College Head; $\mathrm{SH}=$ School Head CRC = College research coordinator; $\mathrm{RC}=$ School research coordinator; $\mathrm{TL}=$ interdisciplinary research team leader; $\mathrm{TM}=$ interdisciplinary research team member. We intentionally used quotes from numerous participants so that no one voice would dominate.

\section{The Sample}

One hundred and twenty seven research active academic staff responded to our survey. Thirty three of them did not provide demographic information but their responses to our questions were used. Ninety four people provided demographic information. The majority of these was male 
(67\%). Different age groups were identified (25.5\% were in the $30-40$ category; $30.9 \%$ in the 40 50 age category; and $31.9 \%$ in the 50-60 age group). There were $40.6 \%$ professors, $36.5 \%$ lecturers, $16.7 \%$ researchers and $6.3 \%$ associate professors. Also $33 \%$ indicated that they were a research team leader, $34 \%$ indicated that they were a research team member and $87 \%$ indicated they were a member of the academic staff. None of the respondents indicated that they were an administrator, at any level of the university. This may mean that no administrators completed the survey or that they chose not to identify themselves as an administrator.

Most respondents (64.8\%) were interested in interdisciplinary research and most $(84.2 \%)$ were actively involved in it, although only $31.4 \%$ of the respondents indicated their research was primarily interdisciplinary, with $59.8 \%$ indicating partially interdisciplinary. In addition, $73.2 \%$ of the respondents had published in interdisciplinary journals, with $58.3 \%$ of respondents having published more than 3 interdisciplinary articles, and 30.2\% more than 5, in the last five years.

\section{Findings}

\section{Research Question 1: Perceptions about the nature and benefits of interdisciplinary research}

It might be suggested that such a comprehensive reorganisation of a major university would be underpinned by clear understandings of what was expected by the term 'interdisciplinary research', yet a document search of the university website shows that there are many references to different terms when focusing on cross disciplinary activity that leads to the conclusion that the various terms 'cross-disciplinary', 'multi-disciplinary' and 'inter-disciplinary' are used to describe similar research activities. Further, in papers and presentations created by university administration, these terms also appear to be used interchangeably. For instance, a single document proposing structural reforms at the university contained no less than 17 different terms to describe IDR (Great Western University, 2010). This suggests that there is not a clear understanding of what each of the various terms being used means at the administrative level.

It is little wonder then that staff too, use the terms interchangeably or are unsure of what they mean. Question 18 was an open-ended question and asked respondents to articulate the difference between interdisciplinary and multidisciplinary research. Of the 66 respondents, $38 \%$ had no understanding of the difference between multidisciplinary and interdisciplinary research, $47 \%$ had some understanding of it and only $22 \%$ had a good understanding. A concern was expressed that the lack of clarity of what the terms meant and the use of differing terms 
interchangeably was confusing, even to those who led research teams. 'The jargon keeps shifting' (TL4).

The data suggest there is a lack of clarity both by the university administrators and by the staff at Great Western University on what the terms multidisciplinary (MDR) and interdisciplinary research (IDR) mean. The terms are used interchangeably at all levels and nowhere is there any statement that helps to define the various levels of collaboration required for each.

Overall $78.2 \%$ of staff believed that IDR was as important as disciplinary research, a majority of staff $(71.5 \%)$ indicated that they had benefited from being involved in IDR and $75.4 \%$ agreed that their own IDR team experience was positive and only $4.2 \%$ felt it was negative. Overall, the data indicate that people enjoyed working within their IDR team and that they were productive.

\section{Research Question 2: Organizing and Supporting Interdisciplinary research}

Great Western University organizes its IDR activities using four structures: institutes, centres, networks, and clusters. Research institutes, centres, and networks pre-date the restructuring plan of 2010. Clusters were introduced with recent restructuring efforts. We first describe these structures and then turn to the perceptions of academic staff as to the support for IDR and its effectiveness.

\section{Institutes}

Research Institutes are autonomous units within the College framework and are not subordinate to Schools. They may cross college boundaries and are responsible for thematic, multidisciplinary research addressing strategic research questions demanding multi-disciplinary collaboration and dedicated orchestrated resources. They are expected to deliver postgraduate training at the masters' level.

One school head saw Institutes as the 'top dogs here' and an IDR team member suggested 'On the ground, the assumption is that Institutes are where the 'real' research is conducted.' The major concern directed toward the Institutes was that they take resources away from the Schools 'the shift away from departments to Institutes will further undermine departments through 'asset stripping' by poaching the best researchers' (AS17) and 'Academic 
staff members are invited to participate in the research. They can buy out of their teaching responsibilities and their employment status changes. Even when they are 'bought out' no money comes back to the school.' (SRC2) This reallocation also included credit for research. 'When it comes time to get credit for the research they [Institutes] insist that it be published with Institute acknowledgement and credit does not work its way back to the school or the college.' (RC1; TL1)

\section{Centres}

Research Centres and Centres of Excellence exist within and/or between Schools, Institutes and Colleges. They do not need to be sub-divisions of these larger structures but most are. The mission of a Centre is more developmental than an Institute. Centres have a long standing at Great Western University and did not generate many comments. The few comments that were shared pertained to the closing of cherished Centres during the restructuring process.

\section{Networks}

Networks are a recent University strategy to foster IDR and multidisciplinary activities but predate the 2010 restructuring. They are affiliation oriented structures and conveners have no line authority over members. There are two types of networks: visible ones that operate across the University and have a small budget line and invisible networks formed by academic staff either with colleagues at Great Western University or with colleagues in other universities.

In both visible and invisible cases, the work comes off 'the academic staff's backs.' One convener said, 'It's my hobby.' She whimsically said, 'It really would be nice if the University would recognize the work and let it count in my workload.' (TL3) The work forms around common interests but it is difficult to see research impact because research that ends in publication is credited to individuals, colleges, and schools rather than the network, unlike the case for institutes. The general assumption offered by several respondents is that the networks work when they are led by a passionate leader and have committed academic staff associated with the network. Lack of administrative support is commonly cited as an impediment to greater productivity.

\section{Clusters/Restructuring}


With the reorganization, school departments were eliminated and in most Colleges and some schools a Cluster strategy was utilized to organize both research and teaching duties. In some Schools they are seen as new pseudo departments. Academic staff were either assigned or voluntarily affiliated with a Cluster, and the Clusters unintentionally became perceived as another managerial level rather than as a support system to promote research. In other schools clusters are used to identify research areas similar to visible networks at the university level.

\section{Support for Interdisciplinary Research}

Table 1 provides the responses to survey questions related to how IDR is led at Great Western University. A clear majority (70.6\%) of the respondents recognised the need for good leadership to enable IDR to flourish. Whereas $58 \%$ of respondents felt leadership at the team level for IDR was provided, there was less support (27.2\%) for leadership being shown at the College level 'Leadership of research, and facilitation of a vibrant research culture is needed - but the management in here simply don't have the leadership skills to enhance this' (AS21).

\section{Table 1 about here}

Over one third of the respondents (34.6\%) felt that the systems at the Great Western University were cumbersome, for example 'The new system has inhibited, not helped, conversations between disciplines' (AS7) and 'The cumbersome arrangements for Research Centres reveal some of these problems.' (AS23)

Table 2 provides the responses to questions related to whether the University's efforts to introduce IDR have been successful. Although there is an indication that a majority of respondents $(70 \%)$ felt that there had been success at the IDR team level, there was considerably less support for the success of attempts by the University (16.6\%) and Colleges (12.8\%) to increase this activity. Only $13.5 \%$ of the respondents felt that the teams set up at the College level were working well.

Table 2 about here 
Some staff were positive 'I have found support for this at the College and University level to be excellent.' (AS20) but others were more cautious 'I think the University's impulse with this has been good, but it's an uphill battle. (AS16) Most negative comments connected the recent restructuring of the University with the attempt to improve IDR. For example, 'senior management seems to labouring under the misconception that the re-organisation would help interdisciplinary research - it doesn't' (AS22) and 'The SMG's obsession with promoting this through reorganisation has hindered rather than helped to organise interdisciplinary research.' (AS19)

Others suggested that this was something that was being done for short term purposes 'it's only being promoted as a means to securing funding - it's about money, not impact or knowledge.' (AS9) Still others were concerned about the perceived top down approach that suggested that all staff should be involved in this kind of research 'Real interdisciplinarity has to grow from below, not be imposed from above.' (AS18) Finally, some saw the restructuring of the University and the promotion of IDR as an attack on the previously held departmental structure. 'Interdisciplinary research should be seen as complementary to departmental research, not a substitute, and not imposed.' (AS23)

The data suggest that although most staff agree with the concept of IDR there is a high level of concern about the way in which the university has attempted to introduce and promote this form of research.

\section{Views about the Support for IDR}

Great Western's restructuring is only 2 years old and it has had some positive effects in attracting new academic staff 'one attraction for coming here was the prospects of interdisciplinary research. I have found that the prospects so far have exceeded my expectations.' (TM4) Others characterize this in a more cautious way. 'I think we are getting there but it has been a slow journey.' (TL4)

These comments reinforce data from our survey where, as seen on Table 2, many respondents were undecided as to whether the University's (41\%) or College's (53\%) attempts to introduce IDR had been successful. Disaggregating the responses showed that $47 \%$ of IDR team members and $53 \%$ of team leaders were undecided about Colleges' success in introducing IDR. 
Several themes emerged to explain or rationalize the slow development of the restructuring efforts. A common refrain is that 'people are busy.' In fact, 'restrictions on staff time' was seen as a major impediment by $49 \%$ and a minor impediment by $32 \%$ of the academic staff responding to the survey. An IDR team member observes that there 'is no recognition in the system that to do things different you have to change work load expectations... Workloads need to be realistic, and especially teaching loads need adjustment if other priorities are being addressed.' (TM4)

A second theme that emerged centered on the nature and number of research themes identified. Respondents said, 'The cross cutting themes are not meaningful and are not that present in my own research or that of my organizational unit.' (TM6) A school research coordinator explained 'My perception in one school is they were crafted by studying what funders were funding. In my school I wrote them to coincide with the mission of our old departments.' (SCR1)

There appears to be significant pent up emotion. For example, respondents say 'Threatening traditional disciplines does not promote interdisciplinarity; it only induces panic and short-term grant-chasing.' (AS2) Opinions were expressed around the freedomaccountability dichotomy that characterizes university traditions. There were academics supporting a disciplinary approach,

Don't make interdisciplinary research mandatory or reward it more than single discipline research. Don't make more money available for it than single discipline research. Don't value it more highly. Don't do these things on account of hoping that you will get more money from funding councils. (AS3)

There were also staff who pointed to the silo-mentality of colleagues.

One of the major barriers to the multidisciplinary approach is the long established tradition of highly focused professional practitioners cultivating a protective (and thus restrictive) boundary around their area of expertise. (TL4) 
A second theme emerged from the perspective that real interdisciplinarity cannot be forced. Comments such'You don't get good positive creative cultures where you have top down managerialism' (AS9) indicate there are members of staff that believe IDR should emerge 'from below, not be imposed from above.' (TL5) One School Head commented, 'Great Western University is a heavily managed institution' and supported the staff view that 'The management structure here is onerous.' (SRC1) These comments suggest that a 'team cannot be pushed together in an academic environment, it usually only works if it forms naturally.' (AS15)

\section{Big Structures and Little Structures}

When Great Western University restructured to support IDR it focused on the big structures of university departments and administrative support staff but paid less attention to the little structures that make a university run well. Perceptions of an incompatible alignment of staff workload, the 2014 Research Excellence Framework (REF) and Professional Development and Review (PDR) activities were seen as impediments to the restructuring efforts of the University, as seen in Table 3.

\section{Staff Time.}

Eighty one percent $(81 \%)$ of the respondents in this study believe that restructuring has placed restrictions on staff time. With the new expectation to contribute to new activities at each level, and with the added pressure from REF 2014, faculty feel beleaguered. 'Many things do not work at Great Western University because there is so little thought given to the workload being created or how people's time will be managed' (AS14) and 'I wonder though, if I'd have been more productive if just allowed to get on with research more than attending meetings (endlessly) across schools and colleges?' (AS16)

Table 3 about here

One interdisciplinary team leader suggested the need to create 'space' for thinking. In practice my experiences of interdisciplinary research have run up against constraints of staff time. It is less clear to me that the academic space exists to promote the conversation and the serendipity which generates good collaboration...From my perspective, you need 
to find ways to enable us to create 'head space.' Ask yourself, do administrative actions create more time or more work? (TL5).

\section{The Research Excellence Framework.}

The REF is the UK government system for assessing the quality of research, and allocates funds based on this assessment. Funding is allocated to a university (and then to a college) based on its performance in research. Individual Performance accounts for $70 \%$ of this assessment. Academic staff submit four items of research output for review which are graded. Publications assessed at level 3 or 4 can cover a professor's salary for 4-5 years. Publications assessed at level 1 or 2 produce no money. The remaining 30\% of the assessment includes assessment of research culture and impact, which in this case means utilization in the field. Publications are reviewed in house, and if selected, are reviewed by a national panel made up of experts drawn from that unit of assessment (for instance, education, music). So the REF activity takes significant staff time; application time, time on internal and external assessment panels. However, the impact of the REF on IDR relates to what is counted as a quality publication.

Many academic staff, but not all, at Great Western University believe the REF is a major disincentive to doing IDR primarily because 'Academic success is defined by success in a DISCIPLINE. One needs appropriate disciplinary publications for the REF' (AS21) and 'the REF is inhibiting because it rates publications in discipline journals higher than other journals.'(TL1) This leads to concerns over how staff will be judged in terms of promotion. The majority of staff felt either negative (33.8\%) or unsure (44.9\%) about the impact IDR had on their chances of promotion 'It is a struggle to get people motivated toward long term benefits which derive from interdisciplinary research when it's short term results which are demanded. With these pressures it's easier to stay in the discipline where the potential is known.' (SH2). This dilemma is summed up by the comment below:

The university wants both interdisciplinary research AND strong REF return.

These are conflicting goals...It is a struggle to get people motivated toward long term benefits which derive from interdisciplinary research when it's short term results which are demanded. With these pressures it's easier to stay in the discipline and potential is known. (AS21) 
The REF documentation does refer to IDR: 'institutions should provide information about how they support interdisciplinary and collaborative research, and panels will give due credit where these arrangements have enhanced the vitality and sustainability of the research environment' (REF 2014: 23) however, this type of research only counts for $15-20 \%$ of the total assessment.

\section{Discussion and Suggestions}

Our specific purpose in this paper was to examine interdisciplinary dispositions, processes, and practices in conducting and nurturing IDR teams at the College and university levels.

It should be noted that the study is limited to a single case and relies on the perceptions of academic staff and administrators responding to our invitations to participate. We made no assumptions about the value of interdisciplinarity or what it would look like within a major university. We also recognize that there are multiple lenses to interpret findings. Leadership is just one. Accordingly, some caution is called for in generalizing our findings.

We extracted several major findings from our results. Leadership is important at both the university and college levels if interdisciplinarity is to thrive. At both levels, the ability to establish direction, alignment and commitment and develop community is often the difference between success and failure. At the centre of success are three variables that work against or for change - culture, communication and commitment (Pisapia 2009). At the IDR team level, and in some of the IDR networks where leaders work in coordination and collaboration roles, these variables have worked. It is less evident at the University level and we would suggest that university leaders should move from working with policies (things) to working with processes (people), engaging academic staff in the work rather than telling them what to do (Basadur, 2004).

The University proactively moved forward to enhance interdisciplinarity in its research and teaching portfolios. The data indicate a willingness of staff to be involved in interdisciplinary projects and an enjoyment and satisfaction when they are. There is less of a consensus about whether this approach should be forced or engineered. Many respondents perceived that this best IDR occurs naturally when people from different fields are allowed to meet, talk, socialize and discover common interests, rather than having this forced upon them. Good leadership and good decision making is required for IDR to thrive. The evidence we 
reviewed at Great Western University indicates that IDR team leaders are succeeding in these roles. At the college and university levels, there is always the need to gain the attention of academic staff so some forcefulness and attention to big structures often required. Command is a natural and useful tool possessed by leaders at this level. The option is to combine command with control or command with coordination. Modern leadership theory suggests that command and coordination are the more productive influence actions at the enterprise level. The evidence we reviewed suggests that these new leadership roles need to be further enhanced. The University has done well with the 'big' structures to enrich and support interdisciplinarity. Those that predate the restructuring seem to have been unaffected or may even have been enhanced, by the restructuring. The prevailing opinion is that newer structures such as clusters have made management easier but not necessarily research.

While discomfort is normal in large change efforts, it cannot be left unattended. People do adjust, adapt, and innovate to new circumstances. However, things go smoother when leaders consider the human issues that impact people's organisational lives when making changes from a transformative perspective. Staff resistance to the restructuring efforts emerge from the small structures, such as clarity of meaning, motivation of staff, misalignment of left over structures, workload, and loss of identity. It might be more productive if leaders in the senior management group move from managing the change to facilitating the change represented by the restructuring by attending to the 'details' cited above by aligning structures and removing barriers that impede success.

One area of contention is the difference between multidisciplinary and interdisciplinarity. The data has shown the many ways these terms have been interpreted and used both by administrators and staff. In fact, in one college $41 \%$ of the academic staff responding did not have any understanding of the differences between the terms. Clarity of mission has not been demonstrated. Is it multidisciplinary or interdisicplinary research that is needed? Multidisciplinary approaches allow the disciplines to pursue their silo thinking. Interdisciplinary approaches are more difficult, and insecurity still exists within staff members. One approach may be to clarify what multidisciplinary and interdisciplinary means within the university, which may encourage people to move from one level of collaboration to the next in a staged way. Sometimes the move to clarity has unintended consequences. The respondents in this study 
clearly said that trying to motivate them toward IDR because funders will fund it is the wrong message for them, even if it is the right message for the university.

Second, IDR must compete with other social and organizational responsibilities and roles of staff. Some individuals have few connections to their colleagues or the collective norms set by programs, departments, and colleges. At the other end of the professional autonomy continuum are professors who make their programs, research, and students the foci of their role as professors, who might become the owners of the reforms. The narrative used by leaders is important. In university cultures, it's important to move in ways that seek not to crush the dominant logic but adjust it, update it, or reset it. This effort will rest on clarifying and simplifying the models of change employed.

Third, the PDR process, the REF is seen as a barrier to the introduction of IDR, especially for young staff. If one is required to be a disciplinary expert for promotion purposes and if the REF process is aligned with units of assessment based only on individual disciplines, then IDR will only be open to those who have already been promoted and have already achieved the required publications.

Fourth, the perceived increase in people's workloads, without there being any incentives or ways to lessen workloads in other ways is a disincentive. Most large change efforts require the willingness of the staff to engage and own it. However, norms of reciprocity are in effect. From the staff's perspective, if they are interested and committed they will engage willingly. If not, incentives must be applied, but the removal of administrative support staff is the reverse. If new priorities are to be undertaken, workloads need to be thought through and addressed.

\section{Conclusion}

We conclude our paper with three recommendations. Stay clear on focus, extend the benefits of serendipity to more people, and remember that one size does not fit all.

If research is to be the major emphasis, it must be at the centre of the enterprise and resourced. Attention must be paid to the unanticipated consequences such as workload, REF and PDR alignment, and creating a motivational rhetoric. The themes identified must be important enough to draw attention and big enough that staff can identify with them.

Second, develop ways to extend the benefits of serendipity to more people. The way staff is distributed geographically does not lead to informal interactions. Perhaps there is a need 
to develop a Centre where IDR could flourish and where meetings, seminars and conferences are held, or requiring PhD students to be supervised by researchers from different disciplines and schools. These strategies have the potential to a gradual shift in attitudes and values suggested by the University's guiding vision.

Opportunities can be identified for the lone researcher. Staff is positive about their experiences of IDR but many are negative about current attempts to promote this, seen by some as privileging IDR over other types of research. Perhaps it is as simple as the analogy to the jazz band offered by one of our respondents. 'It's like the jazz band - we can agree on the direction, but don't tell me how to blow the notes or where to put my fingers.' Whatever stance University leaders and academic staff take, the key to promoting interdisciplinary work is to attract and retain academic staff that are consumed by academic life and are passionate about the work. The challenge for Great Western University is to continue to forge agreement on expectations, to understand the impediments to these expectations and to correct them.

\section{References}

About research at Oxford (n.d.) Retrieved August 12, 2012 from http://www.ox.ac.uk/research/about_research_at_oxford/index.html

Ahuja, G. (2000). Collaboration networks, structural holes, and innovation.: A longitudinal study. Administrative Science Quarterly, 45(3) 425-455.

Basadur, M.S. (2004). Leading others to think innovatively together. Creative Leadership . Leadership Quarterly, 15, 103-121.

Bass, B. M. (1990). Bass and Stogdill's handbook of leadership: Theory, research and managerial applications (3rd ed.). New York: Free Press.

Blake, R. and Mouton, J. (1961). Group dynamics - Key to decision making, Houston: Gulf Publishing Co.

Boix Mansilla, V., \& Gardner H. (2003). Assessing interdisciplinary work at the frontier. An empirical exploration of 'symptoms of quality'. Available at http://www. interdisciplines.org CNRS and Institut Nicod, Paris.

Bourdieu, P. (1886). The forms of capital in J.G. Richardson (Ed.), Handbook of theory and research for the sociology of education, Greenwood, New York (1986), pp. 241-258

Branscomb, L., Holton, G., and Sonnert, G. (2001) Cutting edge Basic Research in the Service of Public Objectives: A Blueprint for an Intellectually Bold and Socially Beneficial Science 
Policy. Consortium for Science Policy Outcomes, Arizona State University, May 2001. Available on-line at http://www.cspo.org/products/reports/scienceforsociety.pdf

Burns, J. (1978). Leadership. New York, NY: Harper \& Row.

Burt, R. (1992). Structural holes: The social structure of competition. Cambridge, MA: Harvard University Press.

Clark, P. (1993). A typology of multidisciplinary education in gerontology and geriatrics: are we really doing what we say we are? Journal of Interprofessional Care, 7, 3, 217-227.

Coffey, A., B. Holbrook and P. Atkinson (1996) 'Qualitative Data Analysis: Technologies and Representations', Sociological Research Online, vol. 1, no. 1 retrieved July 10, 2012 from <http://www.socresonline.org.uk/1/1/4.html>.

Coleman, J. (1988). Social capital in the creation of human capital. The American Journal of Sociology, 94. S95-S120

Constitution of Research Centres, n.d.) Great Western University, Retrieved August 4, 2012, http://www.gla.ac.uk/media/media_185779_en.pdf).

Cox, J., Pearce, C., \& Perry, M., (2003). Toward a model of shared leadership and distributed influence in the innovation process: How shared leadership can enhance new product development team dynamics and effectiveness. In C. L. Pearce \& J. A. Conger, Shared leadership: Reframing the hows and whys. Thousand Oaks, CA: Sage.

Cresswell, J. (2009). Research Design: Qualitative, quantitative, and mixed methods approaches, $3^{\text {nd }}$ ed. Thousand Oaks, CA: Sage Publications.

Drath, W. (2001). The deep blue sea: Rethinking the source of leadership. San Francisco: Jossey-Bass.

Drath, W., McCauley, C., Paulus, P., Velsor, E., O’Connor, P., \& McGuire, J. (2008). Direction, alignment, commitment: Toward a more integrative ontology of leadership. The Leadership Quarterly. 19, 635:653

Dykes, T., Rodgers, P. \& Smyth, M. (2009). Towards a new disciplinary framework for contemporary creative design practice. CoDesign 5 (2):99-116.

Fayard, A. (2010). Multidisciplinary research: Challenging and rewarding or too damn difficult? Retrieved <ay, 2012 from http://blogs.poly.edu/bsww/2010/01/16/multidisciplinaryresearchchallenging-and-rewarding-or-too-damn-difficult/

Fiedler, F.E. (1967) A Theory of Leadership Effectiveness. New York: McGraw-Hill. 
Fischer, G. (2004). Social creativity: Turning barriers into opportunities for collaborative design. Proceedings of the eighth conference on Participatory design: Artful integration: interweaving media, materials and practices, 1, 152-161.

Fu, P.P, \& Yukl, G. (2000). Perceived effectiveness of influence tactics in the United States and China. The Leadership Quarterly, 11(2), 252-266.

Goldstein, J., Hazy, J. K., \& Lichtenstein, B. (2010). Complexity and the Nexus of Leadership: leveraging nonlinear science to create ecologies of innovation. Englewood Cliffs: Palgrave Macmillan

Great Western University (2010) Organisational Structures: Proposals for Change. (anonymous, online)

Gronn, P. (2002). Distributed leadership as a unit of analysis. Leadership Quarterly, 13, $423-451$.

Harvard creates new, University-wide committee to guide interdisciplinary efforts in science. Harvard Gazette (Aug. 27, 2012). Retrieved August 12, 2012 from http://news.harvard.edu/gazette/story/2007/01/harvard-creates-new-university-widecommittee-to-guide-interdisciplinary-efforts-in-science/

Hersey, P., \& Blanchard, K. (1988). Management of organizational behavior. Englewood Cliffs, NJ: Prentice Hall.

House, R. J. (1971). A path-goal theory of leader effectiveness. Administrative Science Quarterly, 16: 321-338.

Huutoniemi K., Klein, J., Bruun, H., \& Hukkinen, J. (2010). Analyzing interdisciplinarity: Typology and indicators. Research Policy 39 (1):79 -88.

Klein, J. (1990). Interdisciplinarity: History, Theory, and Practice. Detroit, MI: Wayne State University Press.

Klein, J. (1996). Crossing boundaries: Knowledge, disciplinarities, and interdisciplinarities. Charlottesville, VA: The University Press of Virginia.

Lichtenstein, B., Uhl-Bien, M., Marion, R., Seers, A., Orten, J. D., \& Schreiber, C. (2006). Complexity leadership theory: An interactive perspective on leading in complex adaptive systems. Emergence: Complexity \& Organization, 8, 2-12.

Lin, N. (2001). Building a network theory of social capital. CONNECTIONS, 22(1), 28-51

McGrath, C., \& Krackhardt, D. (2003) Network conditions for organizational change. The Journal of Applied Behavioral Science. 39(3), 324-336. 
McNamee, S., \& Gergen, K. J. (1999). Relational responsibility: Resources for sustainable dialogue. Thousand Oaks, CA: Sage.

Metzger, N. and Zare, R. N. "Interdisciplinary research: From belief to reality," Science 283(5402):642-643, 1999.

Miles, M. B. \& Huberman, A. M. (1994). Qualitative data analysis (2nd ed.). Thousand Oaks, CA: Sage

National Academy of Sciences (2004). Facilitating Interdisciplinary Research. National Academies of Science, National Academy of Engineering, and Institute of Medicine of the National Academies. Washington DC: The National Academies Press.

Pirrie, A., Wilson, V., Elsegood, J., Hall, J., Hamilton, S., Harden, R., Lee, D. \& Stead, J. (1998) Evaluating multidisciplinary education in health care. Edinburgh: SCRE

Pisapia, J. (2009). The strategic leader. Charlotte: Information Age Publishers.

Pisapia, J., Townsend, T. \& Razzaq, J. (2012). Interdisciplinary research: Perceptions, Teams and Networks: A Report to the Adam Smith Research Foundation, University of Glasgow.

Podsakoff, P.M., MacKenzie, S.M., Lee, J., \& Podsakoff, N.P. (2003). Common method variance in behavioral research: A critical review of the literature and recommended remedies. Journal of Applied Psychology, 88, 879-903.

Putnam, R. (1993). Making democracy work: Civic traditions in modern Italy. Princeton: Princeton University Press.

REF (2014) Assessment framework and guidance on submissions (REF 02.2011 July 2011) available at http://www.ref.ac.uk/pubs/2011-02/ downloaded September 02, 2012.

Research at Cambridge (2011). Retrieved August 12, 2012 from http://www.cam.ac.uk/research/about/

Rhoten, D. 2003. A Multi-Method Analysis of the Social and Technical Conditions for Interdisciplinary Collaboration. Final report to the National Science Foundation. Retrieved July 4, 2012 from http://www.hybridvigor.net/interdis/pubs/hv_pub_interdis2003.09.29.pdf

Roberts, J. A. and Barnhill, R. E. “Engineering Togetherness: An Incentive System for Interdisciplinary Research.” ASEE/IEEE Frontiers in Education Conference. Reno, NV. October 10-13, 2001. 
Salter, L. \& Hearn, A. (1996). Interdisciplinarity. In L. Salter and A. Hearn, ed. Outside the lines: issues in interdisciplinary research. Montreal: McGill-Queen's University Press.

Stanford Research (n.d.)Retrieved August 12, 2012 from http://www.stanford.edu/research/

Stokols D, Misra S, Moser R., Hall K, \& Taylor B. (2008a). The ecology of team science: understanding contextual influences on transdisciplinary collaboration. American Journal of Preventive Medicine, 35, S96-S115.

Stokols, D., Hall, K., Taylor, B., \& Moser, R.(2008b). The Science of Team Science: Overview of the Field and Introduction to the Supplement. American Journal of Preventive Medicine, 35, S77-S89.

Tenkasi, R. \& Chesmore, M. (2003). Social networks and planned organizational change. Journal of Applied Behavioral Science, 39(3), 281-300.

Triandis, H. (1995). Individualism and collectivism. Boulder, CO: Westview Press.

Tsai, W. \& Ghoshal, S. (1998). Social capital and value creation: The role of intrafirm networks. The Academy of Management Journal, 41(4) 464-476.

Uhl-Bien, M. (2006). Relational leadership theory: Exploring the social processes of leadership and organizing. Leadership Quarterly, 17, 654-676.

Uhl-Bien, M , Marion, R. \& McKelvey, B. (2007). Complexity leadership Theory: Shifting leadership from the industrial age to the knowledge era. The Leadership Quarterly. 18, 298-318.

Wall, S. \& Shankar. I. (2008). Adventures in transdisciplinary learning. Studies in Higher Education, 33(50, 551-565.

Yin, R. (2003). Case study research: Design and methods (3rd ed.). Thousand Oaks, CA: Sage. 

Table 1

Leadership of Interdisciplinary Activity

\begin{tabular}{|c|c|c|c|c|c|c|}
\hline Statement & $\mathbf{S A}$ & $\mathbf{A}$ & $\mathbf{U}$ & D & SD & Total \\
\hline $\begin{array}{l}\text { Interdisciplinary research requires } \\
\text { good leadership }\end{array}$ & $\begin{array}{l}34.1 \% \\
(43)\end{array}$ & $\begin{array}{l}36.5 \% \\
(46)\end{array}$ & $\begin{array}{l}24.6 \% \\
(31)\end{array}$ & $\begin{array}{l}3.2 \% \\
(4)\end{array}$ & $\begin{array}{l}1.6 \% \\
(2)\end{array}$ & 126 \\
\hline $\begin{array}{l}\text { Training was provided to enable me } \\
\text { to improve my ability to participate } \\
\text { in interdisciplinary research }\end{array}$ & $\begin{array}{l}2.5 \% \\
(3)\end{array}$ & $\begin{array}{l}8.2 \% \\
(10)\end{array}$ & $\begin{array}{l}14.8 \% \\
(18)\end{array}$ & $\begin{array}{l}36.9 \% \\
(45)\end{array}$ & $\begin{array}{l}37.7 \% \\
(46)\end{array}$ & 122 \\
\hline $\begin{array}{l}\text { There is leadership for } \\
\text { interdisciplinary research at the } \\
\text { College level }\end{array}$ & $\begin{array}{l}4.8 \% \\
(6)\end{array}$ & $\begin{array}{l}22.4 \% \\
(28)\end{array}$ & $\begin{array}{l}39.2 \% \\
(49)\end{array}$ & $\begin{array}{l}22.4 \% \\
(28)\end{array}$ & $\begin{array}{l}11.2 \% \\
(14)\end{array}$ & 125 \\
\hline $\begin{array}{l}\text { There is leadership for } \\
\text { interdisciplinary research at the } \\
\text { School level }\end{array}$ & $\begin{array}{l}4.8 \% \\
(6)\end{array}$ & $\begin{array}{l}23.8 \% \\
(30)\end{array}$ & $\begin{array}{l}33.3 \% \\
(42)\end{array}$ & $\begin{array}{l}24.6 \% \\
(31)\end{array}$ & $\begin{array}{l}13.5 \% \\
(17)\end{array}$ & 126 \\
\hline $\begin{array}{l}\text { There is leadership for } \\
\text { interdisciplinary research at the } \\
\text { project level }\end{array}$ & $\begin{array}{l}15.3 \% \\
(19)\end{array}$ & $\begin{array}{l}42.7 \% \\
(53)\end{array}$ & $\begin{array}{l}31.5 \% \\
(39)\end{array}$ & $\begin{array}{l}6.5 \% \\
(8)\end{array}$ & $\begin{array}{l}4.0 \% \\
(5)\end{array}$ & 124 \\
\hline $\begin{array}{l}\text { The systems here are too } \\
\text { cumbersome to work through }\end{array}$ & $\begin{array}{l}26.4 \% \\
(32)\end{array}$ & $\begin{array}{l}18.2 \% \\
(22)\end{array}$ & $\begin{array}{l}36.4 \% \\
(44)\end{array}$ & $\begin{array}{l}14.0 \% \\
(17)\end{array}$ & $\begin{array}{l}5.0 \% \\
(6)\end{array}$ & 121 \\
\hline
\end{tabular}


Table 2

Perceptions of success

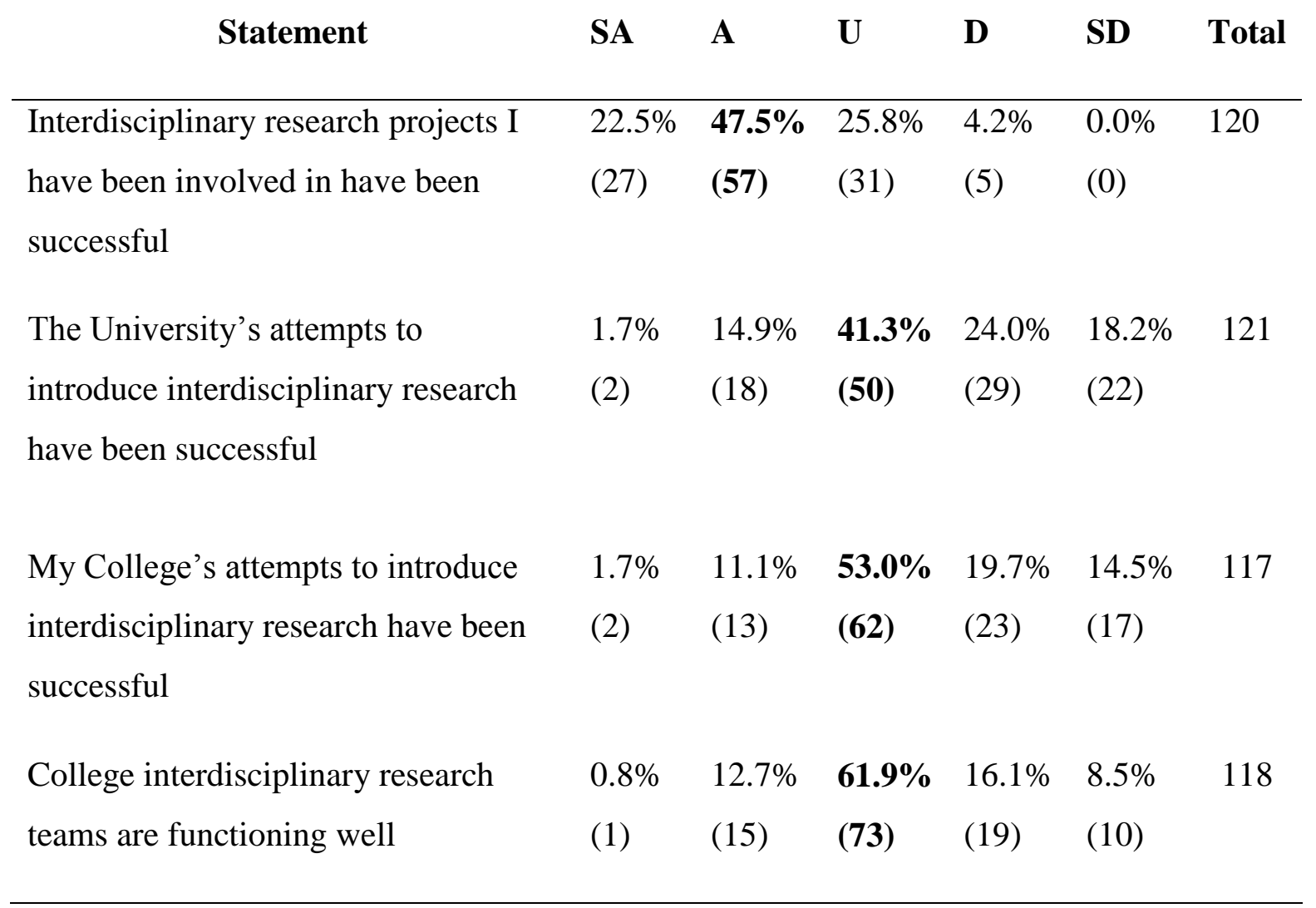


Table 3

Impediments to the Functioning of IDR Teams

\section{Impediments}

Major Minor None \#

Control of Project Funds

Indirect cost recovery distribution

P \&DR Assessment

Restrictions on Staff Autonomy

Restrictions on Staff Time

Availability of venture Capital
32.3\% $\quad 50.5 \% \quad 17.2 \% \quad 99$

(32) (50)

(17)

$24.2 \% \quad 51.5 \% \quad 24.2 \% \quad 99$

(24) (51) (24)

$31.6 \% \quad 34.7 \% \quad 33.7 \% \quad 98$

(31) (34) (33)

$\mathbf{1 8 . 4 \%} \quad 26.5 \% \quad 55.1 \% \quad 98$

(18) (26)

$\mathbf{1 4 . 1 \%} \quad 31.3 \% \quad 54.5 \% \quad 99$

(14) (31) (54)

$\mathbf{4 9 . 0 \%} \quad 32.0 \% \quad 19.0 \% \quad 100$

(49) (32) (19)

$\mathbf{2 5 . 5 \%} \quad 24.5 \% \quad 50.0 \% \quad 94$

(24) (23) (47) 